\section{Strategies for transcending the chaos of societal disruptions}

\section{Chaos of societal disruptions}

\author{
John C. Camillus
}

University of Pittsburgh, Pittsburgh, Pennsylvania, USA

Jeffrey E. Baker

US Army War College, Carlisle, Pennsylvania, USA, and

Anushka I. Daunt and Jungyoon Jang

University of Pittsburgh, Pittsburgh, Pennsylvania, USA

\begin{abstract}
Purpose - This study aims to offer a strategic management response to societal disruptions of the magnitude triggered by the agricultural, industrial and information revolutions. These pose challenges that are much greater and different in kind than the industry-wide disruptions that businesses have learned to manage. Pandemics, climate change, biotech and artificial intelligence guarantee that such societal disruptions will be an inescapable and recurring reality.
\end{abstract}

Design/methodology/approach - The paper builds on the strategic management responses to wicked problems, which possess in microcosm the chaotic ambiguity that characterizes societal disruptions.

Findings - The authors propose a management process that affirms a sense of identity, identifies robust actions, adopts a real-options approach and uses a platform organization.

Research limitations/implications - The primary limitation is that the recommendations and findings are extrapolations of organizational practices in analogous situations. No examples of formal management processes specifically designed to address societal disruptions were identified.

Practical implications - The practical implications are significant. The specific recommendations in the paper directly address strategic management practice in organizations.

Social implications - The social implications are integral to the motivation of the paper as it describes the intrinsic characteristics of societal change and transformation, enabling organizations to interact with society on a dynamic basis.

Originality/value - While there has been growing interest and research into business and industry disruptions, the challenge of societal disruptions, which is the focus of this paper, has not been directly addressed.

Keywords Disruptions, Strategy, Implementation, Strategic management, Identity, Societal change

Paper type Viewpoint

\section{Introduction}

Societal disruptions - of the magnitude triggered by the agricultural, industrial and information revolutions - pose challenges that are much greater and different in kind than the industry-wide disruptions that businesses have learned to manage. We can trace societal

(C) John C. Camillus, Jeffrey E. Baker, Anushka I. Daunt and Jungyoon Jang. Published in Vilakshan XIMB Journal of Management. Published by Emerald Publishing Limited. This article is published under the Creative Commons Attribution (CC BY 4.0) licence. Anyone may reproduce, distribute, translate and create derivative works of this article (for both commercial and non-commercial purposes), subject to full attribution to the original publication and authors. The full terms of this licence may be seen at http://creativecommons.org/licences/by/4.0/legalcode
Received 27 July 2020 Revised 3 August 2020 Accepted 4 August 2020 
$\mathrm{XJM}$

$17,1 / 2$

disruptions (Toffler, 1970, 1980, 1990) back to when Homo sapiens first engaged in agriculture, transforming bands of foragers into a paternal, feudal society that invented accounting and built the pyramids and medieval cathedrals. The industrial revolution created gritty cities, nuclear families and alienated major segments of society, and the information revolution (Maynard and Mehrtens, 1993) has upended societies and countries. These disruptions have continued to occur with more frequency, leading not to the question of whether another disruption will occur, but when and what will it be? Today, it is predicted that the next societal disruption may relate to the area of artificial intelligence (AI) or the biotech industry. With the advancements in AI and technology, and the imminence of the Kurzweil singularity, the life we see in science fiction, in movies such as Alita, Blade Runner, Terminator and The Matrix may become all too real. Societal disruptions create a host of "wicked problems" (Camillus, 2008) - resulting from changed economic systems, transformed political processes, revolutionary technologies, altered policies and regulations, shifting mores and a modified understanding of personal success and what constitutes a good life.

We offer a strategic management framework that is designed to address such societal disruptions. When a societal disruption occurs, it is usually accompanied by a shift in society's perception of who is responsible for coping with the change, which may lie beyond the capability of the government or any one entity to manage. As societal disruptions occur, we argue that this shift is best addressed by a combined effort of multiple organizations.

The keys are that firms need to develop a sense of identity that transcends these disruptions, using planning techniques that can cope with wicked problems, and develop platform organizations to formulate and implement effective strategic responses. In a more tangible sense, we can already see firms begin to take these steps to address potential disruptions in arenas such as health care and information technology. Companies such as Alphabet, Amazon and even Comcast (Christina Farr, 2019) are taking steps to stay relevant in shifting societal contexts.

We begin our paper with a definition of a societal disruption and its attributes. Next, we discuss a process designed to manage these disruptions. We conclude with an example of how platform organizations function to address societal disruptions.

\section{Disruption canvas}

To understand how societal disruptions differ from other types of disruption, we use the canvas below (Figure 1). We evaluate the types of disruption based on six features: impact, frequency (of occurrence), number of drivers of change, origin (internal or external), changing values and management innovation (new processes needed).

The first type of disruption is incremental change, which is captured by Quinn (1989). Here, multiple evolutionary changes require firms to make modifications to their operations but would not cause significant change from their normal routines. These disruptions rarely cause firms to change their values or create new processes to address them. They are often a culmination of many different driving forces that are based largely within an organization. Characterized and driven by cumulative changes in organizational subsystems, these disruptions tend to occur most frequently compared to other disruptions, and have the least significant impact on the firm as a whole.

The next type of disruption is Christensen's disruptive innovation, which is when technological changes cause significant changes to the market and firms (Bower and Christensen, 1995; Christensen and Overdorf, 2000). These disruptions are typically driven by a single technological innovation but do not have enough of an impact on a firm to cause it to re-evaluate and change its core values. Firms do not always need to create new 


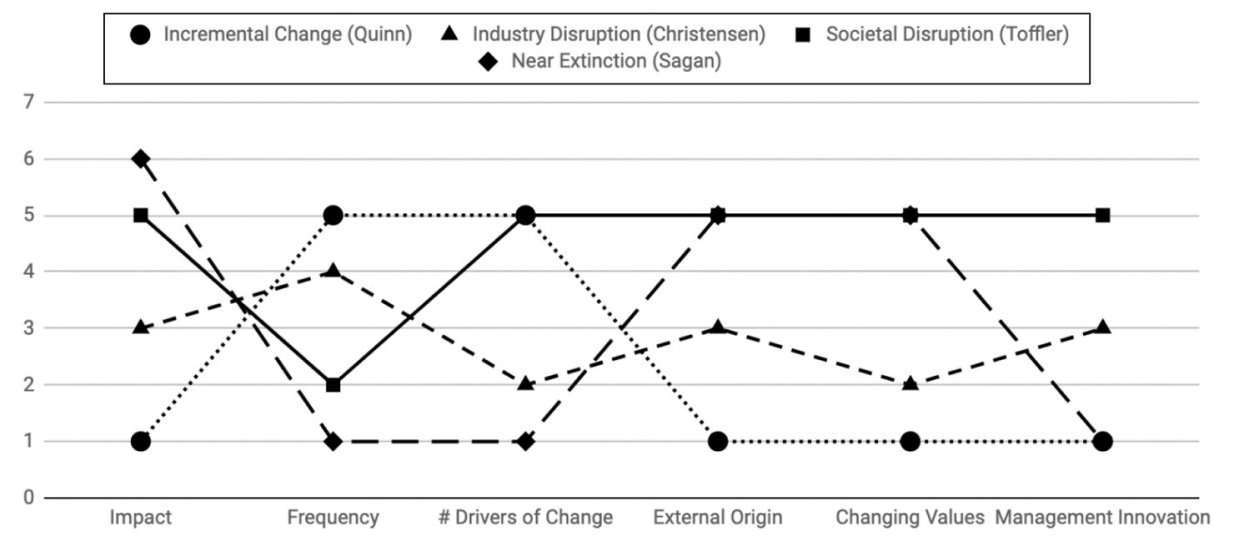

processes to address the change, which can be originated within the firm or from external sources. These disruptions impact firms more than an incremental change, but less than societal disruptions or a near-extinction event. Additionally, in today's world, these disruptions, though discrete, occur relatively frequently.

The third type of disruption is societal disruption, evocatively discussed by Toffler (1970). These are disruptions that change the way in which society thinks, acts and functions, and significantly alter the processes for individuals, firms, non-governmental organizations (NGOs) and government organizations. Though dramatic in their impact, they can be quite difficult to predict and plan for. Societal disruptions have a significant impact on a firm. Firms must often re-evaluate their values and create new management processes to address these disruptions. The Black Lives Matter movement in the USA, for example, has forced a re-examination in many firms of their implicit values and practices. Societal disruptions are not ordinarily caused by one driving force, but rather result from a combination of multiple, external driving forces. Additionally, even though societal disruptions are occurring with increasing frequency, they are still relatively uncommon.

The last type of disruption we identified is near extinction (Sagan, 1983). These are chaotic events that have a disastrous impact on the world, such as a meteor strike or nuclear war. Because of the overwhelming impact and (hoped for) rarity of such a disruption, further consideration of this type of disruption is probably not meaningful.

Before we discuss how firms should manage societal disruptions, we must first discuss the stage or dynamics of these disruptions and when a firm should act. Social disruptions can occur at any time but looking at past experience they take time to build up and arrive at the stage of maximal impact. Climate change and the Kurzweil singularity are good examples of such likely future disruptions. Similar to Gilbert's (2003) explanation of the three phases of disruptive technologies, there are three phases to social disruptions. The first stage is the emergence stage of disruption, where the disruption is nascent and not yet established. At this point, there is the chance it can continue to grow or peter out. During this stage, societal disruptions can be identified through ongoing, continuous sensing and environmental scanning processes. While it requires the recognition and interpretation of "weak signals" (Ansoff, 1975), initiating action at the emergence stage is imperative to increase the probability of mastering the disruption. At this stage, identifying robust actions (Camillus, 2008) that are relevant to both pre- and post-disruption scenarios supports a real 
$\mathrm{XJM}$

$17,1 / 2$

options approach. Robust actions enable a firm to have a head start on the investments and strategic changes that are needed if the disruption takes hold.

The second stage is when the disruption is clearly apparent. This is when the disruption is established in society and has begun visibly impacting the way that society thinks and functions. When it is clear that the disruption is firmly established, and the nature of the disruption is better understood, the firm can then, in line with real options thinking, commit to major investments. There is still room for firms that have not anticipated the disruption to act; however, they will be behind other firms who have identified robust actions and prepared for the disruption prior to its taking hold, creating a future that is better aligned with their aspirations and capabilities.

The third stage is the aftermath of the disruption. This is when the disruption has become the norm and society has adapted to the societal disruption. Firms that begin to address the disruption at this stage will find themselves in a difficult situation, in a defensive posture, reacting to the changes, with a limited capacity to profit from the disruption.

\section{Process for managing societal disruption}

The strategic management process that we offer responds to the properties of societal disruption - changing values, management process innovation, the number of drivers of change, origin, impact and frequency. The process consists of the following eight steps:

(1) identifying and anticipating a societal disruption;

(2) defining the firm's identity;

(3) defining a domain in which to respond to the disruption;

(4) initiating the building of a platform organization;

(5) developing and sharing a vision of a preferred future;

(6) generating possibility scenarios and determining robust actions;

(7) learning from the implementation of robust actions; and

(8) targeting and making strategic investments.

Repeated cycling through the last three steps of the process may be necessary, until the effects of the disruption stabilize and optimal strategies are developed.

The first step of the process, the identification of a nascent societal disruption, requires that a continuous environmental scanning process be in place. Such processes have been described extensively in the literature on strategic planning (Ansoff, 1975; Thomas, 1980; Fahey et al., 1981; Camillus and Datta, 1991; March et al., 1991) and do not require further explication.

Following step (1), the identification of a nascent societal disruption, the firm needs to rethink and redefine its identity (Albert and Whetten, 1985) in the context of the changed world and changing mores that characterize the new world. The construct of identity has gained much recognition in the literature (Livengood and Reger, 2010; Lok, 2010; Nag et al., 2007; Santos and Eisenhardt, 2005).

Defining the organization's identity is the most critical step in the process of managing a societal disruption. The traditional ways in which organizations have been defined cannot be expected to endure through a societal disruption. It is apodictic that traditional definitions such as the existing mission or concept of business (Abell, 1980), existing strategy and strategic goals (Porter, 1980), existing boundaries defined by their activities and the interdependence of their activities (Thompson, 1967) or transaction costs 
(Williamson, 1981) and existing structure (Chandler, 1962; Rumelt, 1974), cannot be the same following a societal disruption.

The construct of identity, whether of a person or an organization, consists of what is core, enduring and distinctive about the individual or entity. The existing literature (Albert and Whetten, 1985; Camillus, 2011, 2016) postulates that the firm's identity is best articulated by identifying its core values, its enduring aspirations and its distinctive competencies.

Following these two steps, the firm is in a position to begin defining the domain in which it is best suited to address the disruption. Experience has shown that over time, the domain in which organizations operate can change substantially and even dramatically. For instance, PPG Industries, which began its existence as "Pittsburgh Plate Glass," a manufacturer of sheet glass, no longer is in the glass business but today is primarily in the business of architectural and automotive coatings. The example of IBM is even more telling. At one time, IBM was essentially a manufacturer of mainframe computers but has progressed through various iterations to focus on cloud computing and the knowledge business.

Following a societal disruption, organizations would necessarily have to consider how the domain in which they are operating has transformed. For instance, following the disruption caused by the COVID pandemic, Melitta, the German maker of the original paper coffee filter, could move into the domain of personal protective equipment; Amazon could affirm its role as the logistics lifeblood of the American economy; and residential academic institutions, such as the Indian Institutes of Management, may need to redefine themselves as providers of distance learning.

At this stage in the process, it becomes necessary to begin fashioning or joining a platform organization (Ciborra, 1996) - including, possibly, other firms, government agencies, NGOs and customers. A platform organization is important as a means of effectively enlarging the boundaries of the firm and adding the competencies needed to operate successfully in a new domain (Camillus, 2016).

To enable the entities involved with the platform organization to work in concert, a shared vision needs to be developed. It is hard but necessary to build such a shared vision (Wu et al., 2015). The firm's identity can serve as both an anchor and a beacon for defining such a shared vision. Focusing on "shared value" (Porter and Kramer, 2011; Camillus et al., 2017 ) is the means through which conflicts can potentially be resolved.

The fairly well-defined process of developing possibility scenarios and determining robust actions can then be implemented (Camillus, 2008, 2016; Fahey and Randall, 1997). The attractiveness and power of robust actions is that they can eliminate "analysis paralysis" (Lenz and Lyles, 1985), and enable organizations confidently to initiate action, even in the face of unknowable futures.

Implementing the robust actions enables the firm to better understand and learn about the new world. Constantly taking stock of the developments and the ongoing changes caused by the disruption will enable the firm to determine when a particular scenario, from among the possibilities, emerges as the most likely to occur.

At this stage, adopting a real options approach, the firm can determine the strategic investments that are necessary to realize the shared vision. Major investments and more traditional strategic planning analysis can be implemented with confidence when this stage in the process is reached. Of course, the process we recommend will need to be cycled through when the next disruption is discerned through the environmental scanning activity or when it is experienced. 
$\mathrm{XJM}$

$17,1 / 2$

\section{Platform organizations and realization of a shared vision}

Societal disruptions will require novel organizational forms. Venturing into new domains will require new competencies, which may require major changes in the organization and perhaps also require alliances with partners that possess complementary capabilities needed in the post-disruption context.

In 1996, Ciborra described an organization that is able to meet frequent, sudden and radical changes, not only in products markets and technologies, but in its very identity as well as the industry in which it functions (Ciborra, 1996). He called this organization a "platform organization." Creating a platform organization or allying with one would probably enable a firm to transcend or at least survive a societal disruption.

We model the organization architecture needed to deal with societal disruptions after Ciborra's recommended organization. The platform organization is an innovative design. It has the ability to quickly and seamlessly integrate elements of other firms, NGOs, governmental agencies and any other organization that shares a common set of values, and possesses the complementary capabilities needed to address a societal disruption. All elements of Porter's generic value chain (Porter, 1985) will need to be revamped (Porter and Kramer, 2011) to accommodate and ally with partners. Not only is a platform organization able to accept elements of other organizations, it is able to break off elements of itself to integrate with other organizations and receive these elements back as required.

However, this organization of the future will not work without a common and agreed upon framework that allows partnering organizations to shift resources, quickly and efficiently, to the platform organization. We envision this framework as a large pool of organizations that develop a common set of standards, processes and routines that allow a member of one organization to shift from one organization to another without disruptions in pay, leave, benefits or promotion opportunities. While disagreements will occur over items such as intellectual property, residual rights of control and new assets developed by the platform organization, the framework already has an agreed upon mechanism for resolving these unforeseen issues. At the core of the framework is a shared belief that partner organizations will voluntarily recombine assets to address a societal disruption, based on their common values. Creating this background framework will be a monumental task that may require an industry giant, such as an Amazon or Google, to lead the way to establish the standards. In effect, the partnering organizations resemble hegemony, with the founding platform organization acting as the hegemon.

The platform organization differs from ad hoc organizations that come together in the aftermath of a crisis in two distinct ways. The first is a question of timing. The platform organization and the other like-minded organizations in the collective framework share intelligence that allows them to have a robust environmental scanning process that enables them to form before a societal disruption becomes a full-blown crisis. Second, the platform organization and the organizational bricolage that occurs are value-driven entities. They will not only solve pressing needs caused by a societal disruption but also generate value for their organizations. The value generated by the platform organization is shared in accordance with the agreements previously agreed to in the standards established in the framework.

While corporate examples exist in the digital arena, powerful examples outside the digital space are lacking or rare. One organization that closely approximates and evocatively illustrates the characteristics we believe are needed to be effective is the North Atlantic Treaty Organization (NATO). NATO was founded in 1949 as a defense alliance. It is made up of 29 nations across North America and Europe. NATO's primary responsibility is to protect and defend its members' territories and populations against attack. However, like the framework 
that we have suggested, NATO recognizes that the best way to manage conflicts is to prevent them from happening by actively scanning their environment for potential problems and taking early, bold actions to solve the issue before it becomes a full-blown crisis.

NATO has created a domain in which there is a common framework for addressing a future crisis. It has established a mechanism to integrate military, government, political, NGOs and civilian capabilities into an action-oriented element capable of deploying to a potential crisis to stop or mitigate the problem. Rosabeth Moss Kanter (1994) suggests that conscious alignment across five levels of integration is critical for a productive relationship between partnering organizations. The hierarchy of alignment identified by her are labeled the strategic, tactical, operational, interpersonal and cultural levels.

At the strategic level, NATO is a composite of nations bound together by a common set of values and a common purpose. According to NATO's 2010 Strategic Concept, NATO's fundamental and enduring purpose is "to safeguard the freedom and security of all its members by political and military means." In addition to NATO's primary goal of ensuring its member nations' sovereignty, NATO recognizes that "key environmental and resource constraints, including health risks, climate change, water scarcity, and increasing energy needs" are areas of great concern to NATO that will require future planning and operations. NATO, however, operates under the rule of "consensus" of its member nations. Consensus means that all of the member nations must agree, based on commonly espoused values, that the potential problem merits their commitment of resources.

A good example of how NATO functions at the tactical level is in Afghanistan. Over 50 nations (including all 29 NATO countries) have come together under the command of a NATO-led organization called the International Security Assistance Force (ISAF). ISAF had a common purpose in a specific geographic area to solve a pressing problem for the members of NATO. ISAF has been able to incorporate not only military units of its member nations but also military units outside of the NATO framework. These outside units were allowed to conduct operations alongside NATO members because they shared NATO's common vision for Afghanistan. ISAF was not only able to incorporate military units, but also countless NGOs and governmental agencies that were brought into Afghanistan under NATO's aegis to bring relief to the struggling country. While there is little debate that Afghanistan is a complex, indeed wicked problem, that is far from resolved, the NATO framework has allowed an extremely diverse set of organizations, militaries, NGOs and governmental agencies to work together to find a common solution based on their agreedupon idea of a peaceful nation that is no longer a breeding ground for the type of actors that caused the attacks on the USA on September 11th, 2001.

At the operational level, NATO has a published list of agreed-upon standards to ensure interoperability when the different units come together to conduct operations as in Afghanistan. An example of this is having common ammunition, common communication equipment and common fuel, as well as common planning processes. These allow the participating organizations to realize their strategic goals at the tactical level by setting the conditions for successful integration during an operation.

At the interpersonal level, NATO members conduct an agreed upon set of training programs and exercises for both member countries as well as potential partners. An example of this training was in March of 2019 when NATO trained a potential partner's navy to help Tunisia modernize their defense capabilities as well as bring their equipment in line with NATO standards. Training events such as the one above are common and help reinforce the framework that allows a diverse set of organizations to quickly come together with the capabilities required to mitigate a complex problem. These training events allow a

\section{Chaos of societal disruptions}


$\mathrm{XJM}$

$17,1 / 2$

diverse set of partners to nurture personal relationships, develop trust, resolve small conflicts before they escalate and set the conditions for future operations.

At the cultural level, the 29 member nations, as well as a host of other potential partner organizations, have distinct and different cultures. However, the framework that NATO provides allows different cultures such as Turkey, Canada and Estonia to focus on the shared goals and overcome cultural and organizational differences. NATO partners develop close interpersonal ties, mutual respect and trust by conducting joint training. They develop the ability to respect or disregard cultural differences and to focus on the larger, shared vision of NATO.

\section{Conclusion}

Building the capability to cope with societal disruptions is probably a necessity for organizations today. There are technological driving forces such as developments in AI and biotechnology, as well as environmental forces such as climate change and pandemics that will inevitably bring about societal disruptions in the near future. For instance, to cite another environmental challenge, shared and dwindling water resources, exacerbated by climate change, are likely to cause societal disruptions in many areas across the world. China, India and Pakistan, nuclear-armed countries that have engaged in hostilities over decades, uneasily share diminishing water and riparian resources. The vanishing Aral Sea and the post-Soviet challenges of sharing water in the five Central Asian countries - a pivotal and volatile region of the world - has resulted in a fraught situation, requiring drastic changes in their economies and centuries-old traditions, raising the specter of armed conflict. Any viable solution will involve these countries changing their governance practices and their primary sources of wealth and energy. Similarly, Ethiopia, Sudan and Egypt have to rethink their economies and ways of life as a consequence of the massive dam being built in the headwaters of the Nile in Ethiopia.

These many drivers of change are sure to alter fundamentally the way of life for societies across the world. The strategic management framework - processes and structure - that we recommend, we hope, will enable firms that embrace them to overcome the daunting challenge of surviving and prospering through repeated societal disruptions.

\section{References}

Abell, D. (1980), Defining the Business: The Starting Point of Strategic Planning, Prentice-Hall, Englewood Cliffs, NJ.

Albert, S. and Whetten, D. (1985), "Organizational identity”, Research in Organizational Behavior, Vol. 7, pp. 263-295.

Ansoff, H.I. (1975), "Managing strategic surprise by response to weak signals", California Management Review, Vol. 18 No. 2, pp. 21-33.

Bower, J.L. and Christensen, C.M. (1995), "Disruptive technologies: catching the wave", Harvard Business Review, Vol. 73 No. 1, pp. 43-53.

Camillus, J.C. (2008), "Strategy as a wicked problem", Harvard Business Review, Vol. 86 No. 5, pp. 98-101.

Camillus, J.C. (2011), “Organisational identity and the business environment: the strategic connection”, International Journal of Business Environment, Vol. 4 No. 4, pp. 306-314.

Camillus, J.C. (2016), Wicked Strategies: How Companies Conquer Complexity and Confound Competitors, University of Toronto Press, Toronto, ON.

Camillus, J.C. and Datta, D.K. (1991), "Managing strategic issues in a turbulent environment", Long Range Planning, Vol. 24 No. 2, pp. 67-74. 
Camillus, J.C., Bidanda, B. and Mohan, N.C. (2017), The Business of Humanity: Strategic Management in the Era of Globalization, Innovation, and Shared Value, Routledge, New York, NY.

Chandler, A.D. Jr. (1962), Strategy and Structure: Chapters in the History of the Industrial Enterprise, MIT Press, Cambridge, MA.

Christensen, C.M. and Overdorf, M. (2000), "Meeting the challenge of disruptive change", Harvard Business Review, Vol. 78 No. 2, pp. 67-76.

Christina Farr (2019), Comcast is Working on an in-Home Device to Track People's Health, CNBC, available at: www.cnbc.com/2019/05/21/comcast-working-on-home-health-device-similar-toamazon-echo.html

Ciborra, C.U. (1996), "The platform organization: recombining strategies, structures, and surprises", Organization Science, Vol. 7 No. 2, pp. 103-118.

Fahey, L. and Randall, R.M. (Eds) (1997), Learning from the Future: Competitive Foresight Scenarios, John Wiley and Sons.

Fahey, L., King, W.R. and Narayanan, V.K. (1981), "Environmental scanning and forecasting in strategic planning - the state of the art", Long Range Planning, Vol. 14 No. 1, pp. 32-39.

Gilbert, C.G. (2003), "The disruption opportunity”, Sloan Management Review, Vol. 44 No. 4, pp. 27-32.

Kanter, R.M. (1994), "Collaborative advantage: the art of alliances”, Harvard Business Review, Vol. 72 No. 4, pp. 96-108.

Lenz, R.T. and Lyles, M.A. (1985), "Paralysis by analysis: is your planning system becoming too rational?", Long Range Planning, Vol. 18 No. 4, pp. 64-72.

Livengood, R.S. and Reger, R.K. (2010), "That's our turf! Identity domains and competitive dynamics", Academy of Management Review, Vol. 3 No. 1, pp. 48-66.

Lok, J. (2010), "Institutional logics as identity projects", Academy of Management Journal, Vol. 53 No. 6 , pp. 1305-1335.

March, J.G., Sproull, L.S. and Tamuz, M. (1991), “Learning from samples of one or fewer”, Organization Science, Vol. 2 No. 1, pp. 1-13.

Maynard, H.B. and Mehrtens, S.E. (1993), The Fourth Wave: Business in the 21st Century, Berrett-Koehler, San Francisco, CA.

Nag, R., Corley, K.G. and Gioia, D.A. (2007), "The intersection of organizational identity, knowledge, and practice: attempting strategic change via knowledge grafting", Academy of Management Journal, Vol. 50 No. 4, pp. 821-847.

Porter, M.E. (1980), Competitive Strategy: Techniques for Analyzing Industries and Competitors, The Free Press, New York, NY.

Porter, M.E. (1985), The Competitive Advantage: Creating and Sustaining Superior Performance, The Free Press, New York, NY.

Porter, M.E. and Kramer, M. (2011), "Creating shared value”, Harvard Business Review, Vol. 89 No. 1, pp. 2-17.

Quinn, J.B. (1989), "Strategic change: 'logical incrementalism”, Sloan Management Review, Vol. 30, pp. $45-60$.

Rumelt, R.P. (1974), Strategy, Structure and Economic Performance, Graduate School of Business Administration, Harvard University, Boston, MA.

Sagan, C. (1983), "Nuclear war and climatic catastrophe: some policy implications", Foreign Affairs, Vol. 62 No. 2, pp. 257-292.

Santos, F.M. and Eisenhardt, K.M. (2005), "Organisational boundaries and theories of organisation", Organization Science, Vol. 16 No. 5, pp. 491-508.

Thomas, P.S. (1980), "Environmental scanning - the state of the art", Long Range Planning, Vol. 13 No. 1, pp. 20-28. 
$\mathrm{XJM}$

$17,1 / 2$

Thompson, J. (1967), Organizations in Action: Social Science Bases of Administrative Theory, McGraw Hill, New York, NY.

Toffler, A. (1970), Future Shock, Random House, New York, NY.

Toffler, A. (1980), Third Wave, Bantam Books, New York, NY.

Toffler, A. (1990), Powershift: Knowledge, Wealth, and Violence at the Edge of the 21st Century, Bantam Books, New York, NY.

Williamson, O.E. (1981), "The economics of organisations: the transaction cost approach", American Journal of Sociology, Vol. 87 No. 3, pp. 548-577.

Wu, K.-J., Liao, C.-J., Tseng, M.-L. and Chou, P.-J. (2015), "Understanding innovation for sustainable business management capabilities and competencies under uncertainty", Sustainability, pp. 1-35.

Corresponding author

John C. Camillus can be contacted at: camillus@katz.pitt.edu

For instructions on how to order reprints of this article, please visit our website: www.emeraldgrouppublishing.com/licensing/reprints.htm

Or contact us for further details: permissions@emeraldinsight.com 